\title{
Local and systemic effect of azadirachtin on host choice and feeding activity of Macrosiphum rosae on rose plants
}

\author{
Imke Bartelsmeier ${ }^{1,2}\left(\mathbb{D} \cdot\right.$ Michael Kilian $^{1} \cdot$ Cindy J. M. ten Broeke ${ }^{2}\left(\mathbb{D} \cdot\right.$ Daan Mertens $^{2}\left(\mathbb{D} \cdot\right.$ Marcel Dicke $^{2}(\mathbb{D}$
}

Received: 16 June 2021 / Accepted: 5 January 2022 / Published online: 7 February 2022

(c) The Author(s) 2022

\begin{abstract}
Many studies in the last decades addressed the antifeedant and repellent effects of neem (Azadirachta indica)-based pesticides on arthropod herbivores with azadirachtin as the leading active ingredient. However, results for aphids regarding repellence and feeding were often contradictory and mainly based on laboratory studies with self-made neem extracts in high concentrations. Moreover, no data are available on the presence of azadirachtin in the phloem of treated plants-the tissue that most aphids feed on. We investigated how the application of the commercial neem product NeemAzal-T/S onto only one plant half (upper or lower) affects nymphs of the aphid Macrosiphum rosae in clip cages on the untreated plant half. Results for aphid mortality indicate that active ingredients of NeemAzal-T/S are translocated both upwards and downwards in rose plants and that active ingredients are transported in the phloem. Furthermore, we investigated whether NeemAzal-T/S has a repellent or antifeedant effect on M. rosae. A choice test in the greenhouse as well as the quantification of honeydew excretion and electrical penetration graph analysis do not show differences in settling or feeding on untreated and NeemAzal-T/S-treated rose plants. Collectively, our data show that the effect of approved concentrations of NeemAzal-T/S on M. rosae is based on the toxicity after feeding on treated plants, not on starvation.
\end{abstract}

Keywords Aphids $\cdot$ Neem $\cdot$ Azadirachtin $\cdot$ Rose $\cdot$ Antifeedant $\cdot$ Mode of action $\cdot$ IPM

\section{Introduction}

Aphids can cause severe damage to ornamental plants. Direct damage resulting from their phloem-feeding activities includes, for instance, stunted growth and leaf and flower deformations. However, their indirect damage is even more important: aphids can transmit economically significant plant viruses and their stylet punctures in the plant tissue are possible entrance points for plant pathogens such as bacteria or fungi. Additionally, the honeydew that the aphids secrete causes quality losses of plants, especially by promoting the growth of sooty moulds (Brødsgaard and Albajes 1999;

Handling Editor: Heikki Hokkanen.

Imke Bartelsmeier

imke.bartelsmeier@gmail.com

1 Crop Science Division, Bayer AG, Alfred-Nobel-Str. 50, 40789 Monheim am Rhein, Germany

2 Laboratory of Entomology, Wageningen University \& Research, Droevendaalsesteeg 1, Radix building, 6708PB Wageningen, The Netherlands
Alford 2012a, b). One of the major pests of rose plants is the rose aphid Macrosiphum rosae. Its feeding activity on roses, preferably on new shoots and buds, leads to deformed leaves and flowers (Maelzer 1977; Alford 2012b). As an alternative to synthetic pesticides for pest control, biological insecticides from natural sources such as the neem tree (Azadirachta indica) are promising. These products, if properly applied, are characterized by relatively low mammalian toxicity (Raizada et al. 2001; Boeke et al. 2004; Morgan 2009), low persistence in the environment (Szeto and Wan 1996; Sundaram 1996a; Sundaram et al. 1997) and reduced risk of resistance development in the pest (Feng and Isman 1995). However, they often do not provide efficacies as high as found for synthetic pesticides (Bartelsmeier et al. 2022). Beyond causing mortality, additional characteristics of insecticides are beneficial for efficient aphid control: a systemic distribution of active ingredients in the plants and a repellent (before contact to treated plant tissue) or deterrent (after contact) effect. A transportation of active ingredients via the vascular system enhances the intake by insects, particularly by phloem feeders. Especially a distribution to plant parts that are not themselves treated, e.g. shoots and buds 
that developed after the application, and the presence of the active ingredient in the phloem is a benefit for targeting phloem-feeding aphids. In addition, feeding reduction can decrease damage and honeydew production and consequently improve plant quality.

These characteristics are reported for neem products (Mordue and Nisbet 2000; Mordue et al. 2010). The basis for most neem products is an extract from the seed kernels of the neem tree (Azadirachta indica) that contain several natural insecticidal compounds such as azadirachtin, nimbin and salannin (Ley et al. 1993; Kraus 1995). However, the main active ingredient is the terpenoid azadirachtin A, normally referred to as azadirachtin. Biological activity of neem formulations against insects is strongly correlated to their azadirachtin content (Isman et al. 1990; Koul 1999). Azadirachtin treatments to roots and soil were effective against different arthropod species: Sundaram (1996b) and Sundaram et al. (1995) reported, for instance, an impact on spider mites after an upward distribution of azadirachtin in the xylem following root treatment of spruce and aspen plants (Sundaram et al. 1995; Sundaram 1996b). A soil treatment of bean plants led to a significantly higher mortality of thrips and an upward translocation of azadirachtin A and B (Thoeming et al. 2006). Regarding hemipteran insects, significant impacts have been reported, for instance, on whiteflies after soil treatments with neem extract or azadirachtin (Kumar et al. 2005; Karanja et al. 2015).

A clear proof for transport of azadirachtin in the phloem has not been reported so far. Although neem toxins move from the leaf surface to the inner tissue of the leaf in chrysanthemum, only limited movement to other leaves was recorded (Larew 1988). If azadirachtin is only or mainly translocated in the xylem, the control of phloem-feeding insects might be less effective. This may explain a low efficacy of neem products in the control of aphids and phloemfeeding hemipteran pests in general (Schmutterer 1988; National Research Council 1992).

Azadirachtin may have repellent or deterrent effects in insects (Mordue and Nisbet 2000; Mordue et al. 2010). Interference with feeding activity by neem formulations is mainly reported for orthopteran and lepidopteran rather than hemipteran insects. Neem formulations can lead to both primary and secondary antifeedant effects. Primary antifeedant effects, also known as deterrent effects, are caused by contact chemoreception and occur, for instance, in locusts and caterpillars at low concentrations of azadirachtin. These insects often prefer to starve instead of ingesting azadirachtintreated plant material. In the case of aphids, deterrent effects were reported for instance for cereal aphids: Sitobion avenae and Rhopalosiphum padi clearly preferred to settle on untreated winter barley leaves rather than on azadirachtintreated leaves (West and Mordue 1992). Another species, the pea aphid Acyrthosiphum pisum is repelled prior to leaf contact by the azadirachtin-containing product RD-Repelin (Hunter and Ullmann 1992). However, because the product contained also other plant extracts and no blank formulation was tested, this does not prove that repellence was caused by azadirachtin. In contrast, Nisbet et al. (1994) reported that azadirachtin-treated diets in concentrations up to $100 \mathrm{ppm}$ did not affect the settling behaviour of Myzus persicae. Nevertheless, after $24 \mathrm{~h}$, honeydew production by $M$. persicae aphids, a proxy for feeding intensity, was significantly reduced already at $25 \mathrm{ppm}$ azadirachtin, but settling behaviour was still not affected (Nisbet et al. 1994). This suggests that only high concentrations of neem extracts clearly affect aphid settling behaviour (Mordue and Blackwell 1993; Nisbet et al. 1994), but that secondary antifeedant effects after ingestion of treated plant material may occur in aphids at lower concentrations than 100 ppm (Nisbet et al. 1994).

Secondary antifeedant effects are caused by internal feedback mechanisms after ingestion of azadirachtin or other neem toxins (Mordue and Blackwell 1993; Mordue and Nisbet 2010). For this effect, toxins need to be present at the feeding site of the insect. The probing activity of cereal aphids was significantly reduced two and four days after $250 \mathrm{ppm}$ azadirachtin had been applied topically on barley seedlings and after $500 \mathrm{ppm}$ azadirachtin had been applied systemically through roots (West and Mordue 1992).

Repellent or deterrent effects are different among aphid species. Only three of six tested species were deterred by neem seed oil in a study by Lowery and Isman (1993). Furthermore, the rapid disruption of feeding in less than one hour was not attributed to the presence of azadirachtin according to the authors, but other neem toxins seem to be responsible for this effect. Additionally, the antifeedant effect only lasted up to $24 \mathrm{~h}$ (Lowery and Isman 1993). This summary of the literature indicates that aphid species react differently to azadirachtin in terms of settling and feeding and that effective concentrations of azadirachtin are high. Effects caused by 100 to $500 \mathrm{ppm}$ azadirachtin cannot be expected by the currently registered dosage of only $30-50 \mathrm{ppm}$. The kind of formulation-neem oil, watery formulation or the use of acetone or ethanol—and adjuvants might also affect the results.

For $M$. rosae, no results are available regarding a repellent or secondary antifeedant effect caused by commercial neem products under practical conditions. However, a leaf disc laboratory test with an aqueous neem extract solution and second instar $M$. rosae nymphs revealed an effective dose causing 50\% of deterrence by $11 \mathrm{ppm}$ azadirachtin (Koul 1999). This is in the range of currently registered doses of up to $50 \mathrm{ppm}$ azadirachtin, but it is questionable if this effect is also visible in experiments with complete plants under realistic plant growth conditions. For a secondary antifeedant effect, active ingredients of neem extracts need to be available at the feeding site, in the phloem. For this reason, 
the first objective of this study was to assess whether the commercial product NeemAzal-T/S has systemic effects in rose plants and whether active ingredients may be expected to occur in the phloem. We first tested whether treatment with azadirachtin has effects on $M$. rosae nymphs that feed on untreated plant parts, either above or below the treated tissues of the plant. The second objective was to investigate whether a repellent or deterrent effect by the commercial neem product NeemAzal-T/S is present. Repellence was assessed in terms of host-plant choice and we tested whether the general feeding activity of $M$. rosae is affected by commonly registered doses of this product. The feeding was assessed quantitatively by analysing the amount of secreted honeydew as well as qualitatively with the electrical penetration graph (EPG) technique. This technique allows to compare the probing and feeding behaviour of aphids (van Helden and Tjallingii 2000) and can reveal which components of aphid feeding are affected by treating plants with NeemAzal-T/S. The honeydew production of $M$. rosae was assessed for populations of mixed developmental stages to determine the impact for the practical use of this product. Furthermore, because the effect of azadirachtin on mortality of adult aphids is normally low (Lowery and Isman 1994a; Bartelsmeier et al. 2022), repellence and feeding deterrence were investigated for adult aphids. This study thus investigates whether any advantageous effects of NeemAzal-T/S treatment can be expected on adult stages, even when their mortality is not increased.

\section{Materials and methods}

\section{General materials for all experiments}

\section{Insects and plants}

As experimental plants and plants for the aphid culture, miniature rose plants (Rosa hybrida, different Kordana ${ }^{\circledR}$ Classic varieties by W. Kordes' Söhne Rosenschulen GmbH \& Co $\mathrm{KG})$ were used. Rose plants were obtained as freshly rooted cuttings with 3-4 plants per pot. These plants were separated and one or two plants were transferred to pots of 11 or $12 \mathrm{~cm}$ diameter with the soil Einheitserde Classic, Type ED 73, 155 fine. Plants were kept in an air-conditioned greenhouse at $21 \pm 3{ }^{\circ} \mathrm{C}, 60 \pm 10 \% \mathrm{RH}$ and a 16:8 L:D photoperiod. Additional light in the greenhouse was provided by sodium vapour lamps $(400 \mathrm{~W})$ if sunlight intensity outside fell under $120 \mathrm{~W} / \mathrm{m}^{2}$. A few days after transplanting, rose plants were drenched with a liquid fertilizer (Wuxal Top N by Manna, Germany, in a dose of $0.3 \%$ ). Fertilizer application was repeated when required. When needed, fungicides to control mildew were applied, according to current registrations in Germany. Compo Ortiva Universal Pilzfrei (Compo,
Germany) or Bayer Garten Rosen-Pilzfrei Baymat (SBM, Germany) was used. Fungicide treatments were latest done one week before an experiment started to exclude contact effects on aphids. If fungicides were applied, all plants were sprayed to ensure equal conditions. Plants were kept in these conditions for three to four weeks until their use for insect rearing or experiments. At the beginning of an experiment, experimental plants were in a stage where the inflorescence emerged (BBCH stage 51-59, Meier et al. 2009).

As experimental insects, a red phenotype of $M$. rosae was reared, originating from a naturally occurring female on a cultivated rose in Monheim am Rhein, Germany. Rose aphids were maintained on potted miniature roses (Kordana Classic varieties, as described above) in cages made of acrylic glass with three gauze sides $(63 \mathrm{~cm} \times 78 \mathrm{~cm} \times 63 \mathrm{~cm}$ high). Cages were placed in a climate chamber $\left(22 \pm 2{ }^{\circ} \mathrm{C}\right.$, $60 \pm 10 \%$ RH and, a 16:8 h L:D photoperiod). During three to four weeks before every experiment, aphids were reared on the rose variety that was used for the experiment as well.

\section{Treatments}

NeemAzal-T/S (Trifolio-M GmbH, Lahnau, Germany), a common and registered neem-based insecticide in Europe, was used to treat plants. This product is an emulsifiable concentrate with $10 \mathrm{~g}$ azadirachtin A per litre as its major active ingredient (NeemAzal technical, Trifolio-M GmbH 2014). For miniature roses smaller than $50 \mathrm{~cm}$, as used in this study, $0.3 \mathrm{ml}$ of the product per $\mathrm{m}^{2}$ is registered as dose (German Federal Office of Consumer Protection and Food Safety (BVL) 2017). With a slurry volume of $900 \mathrm{l} / \mathrm{ha}$, $3.3 \mathrm{ml}$ product/l water is the recommended dose. Plants were sprayed till run-off while ensuring a complete coverage of plants. Spraying solutions were either applied with a manual trigger spray bottle or a handheld sprayer, operated by compressed air with 3 bar pressure and a $1.1 \mathrm{~mm}$ bore hollow cone nozzle. NeemAzal-T/S was used in different concentrations in most experiments and also its blank formulation was used, referred to as NeemAzal-T/S Blank (provided by Trifolio-M GmbH, Lahnau, Germany). The blank does not contain the NeemAzal-extract, but tensides and plant oils in the same amounts as in the original product NeemAzal-T/S.

\section{Greenhouse conditions and plant care during experiments}

Experiments took place in the same air-conditioned greenhouse as described before with the exception of the EPG experiment. A temperature of $21 \pm 3{ }^{\circ} \mathrm{C}, 60 \pm 10 \% \mathrm{RH}$ and a photoperiod of 16:8 $\mathrm{h} \mathrm{LD}$ were ensured during the experiments. The EPG experiment was conducted under laboratory conditions with $20 \pm 2{ }^{\circ} \mathrm{C}$ and continuous artificial light by 
fluorescent tubes. Plants were watered directly onto the soil as required.

\section{Systemic action of NeemAzal-T/S}

To investigate the systemic effects of NeemAzal-T/S treatments, two experiments were conducted in which the mortality of M. rosae was assessed on untreated plant parts of treated plants. Single rooted cuttings of rose plants (variety Kordana Classic 'Sunstar') were transferred to $11 \mathrm{~cm}$ diameter pots. Before the experiment, all but one shoot were cut at soil level to have a single plant shoot per pot. NeemAzal$\mathrm{T} / \mathrm{S}$ application was done with a handheld trigger spraying bottle. The soil and the part of the plant that should stay untreated were covered with a plastic screen before application. The screen was removed directly after spraying and drying of the plants. The effects of acropetal translocation were assessed by attaching a clip cage with $M$. rosae first instar nymphs on unsprayed leaves above the sprayed plant half. To investigate the effects of basipetal translocation, the clip cage was attached below the sprayed plant half. The scheme of application and position of clip cages are shown in Fig. 1.

In the first trial, mortality of aphids was compared for both translocation directions between an untreated control, $3.3 \mathrm{ml} / 1 \mathrm{NeemAzal-T/S}$ Blank and plants treated with 1.65 , 2.5 and $3.3 \mathrm{ml} / \mathrm{l} \mathrm{NeemAzal-T/S}$. In the second trial, maximum concentrations were higher and treatments were an untreated control, $4.1 \mathrm{ml} / \mathrm{l} \mathrm{NeemAzal-T/S}$ Blank and 2.5, 3.3 and $4.1 \mathrm{ml} / 1 \mathrm{NeemAzal-T/S}$.

After spraying and drying of the plants, three to five randomly selected adult $M$. rosae from the main culture were placed into each clip cage. $24 \mathrm{~h}$ later, adults were removed and the mortality of the remaining nymphs was assessed 1, 4, 6, 8 and 10 days after application. The initial number of first instar nymphs per clip cage was between 6 and 13 individuals in the first trial and 11 to 14 individuals in the second trial. Five rose plants, each with one clip cage, were used per treatment and translocation direction (acropetal and basipetal). In the untreated control groups, clip cages were placed on leaves in similar positions to have comparable conditions of microclimate and leaf age.

Statistical analysis was conducted with R (version 3.1.3, The R Foundation for Statistical Computing, 2015). A Cox proportional hazards model was fitted with the function "coxph" of the package survival (Thernau 2012). A Tukey post hoc test (function "glht" of the package "multcomp" (Hothorn et al. 2008)) was used for a comparison between all treatments regarding the mortality risk for $M$. rosae in the specific treatments and translocation directions (acropetal and basipetal). The mortality in each control group was set as the baseline mortality hazard.

\section{Repellent effects}

Repellence of NeemAzal-T/S was tested in five acrylic glass cages with three gauze sides (dimensions: $63 \mathrm{~cm} \times 78 \mathrm{~cm}$ and $63 \mathrm{~cm}$ high). Ten adult apterous $M$. rosae were released per cage in the middle between one untreated rose plant and one rose plant treated with $3.3 \mathrm{ml} / \mathrm{l} \mathrm{NeemAzal-T/S}$ of the variety Kordana Classic 'Flirt'. Each cage represents one replication. After 1, 2, 5, 24 and $72 \mathrm{~h}$, the numbers of adults on each plant were assessed. The numbers of aphids on untreated and NeemAzal-T/S-treated rose plants per cage were analysed with a generalized linear mixed model (GLMM) on count data with Poisson probability distribution and log-link function (package glmmTMB; Brooks et al. 2017). The model included treatment and time as categorical variables and accounted for repeated measures by including cage identity as random intercept (Zuur et al. 2009). Effect size
Fig. 1 Application scheme for assessing the effects of acropetal (left) and basipetal (right) translocation of active ingredients of NeemAzal-T/S and the future position of clip cages containing $M$. rosae nymphs (clip cage plus aphids were added after spraying and drying of the plants)
Testing acropetal translocation effects:

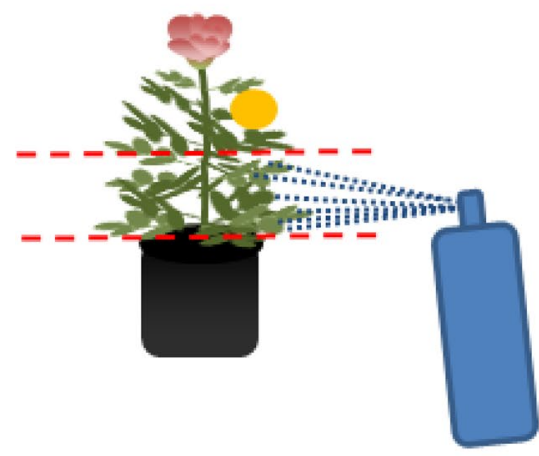

Future position of clip cage with aphids
Testing basipetal translocation effects:

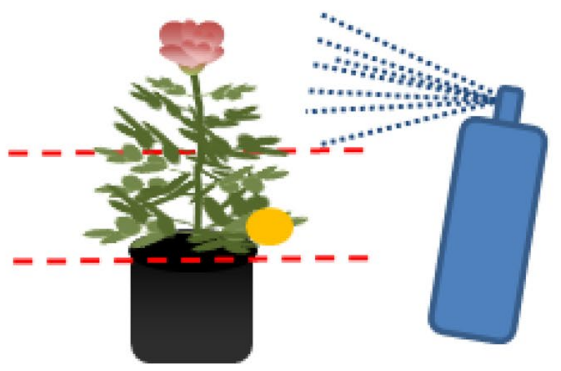

- - - Screen for avoiding spray drift 
and significance of explanatory variables were determined using likelihood-ratio tests. A Tukey post hoc test was used to analyse the data per time point.

\section{Feeding activity: honeydew secretion by $\operatorname{mixed} M$. rosae population or by single adults}

To compare honeydew secretion by $M$. rosae on untreated and NeemAzal-T/S-treated rose plants, an experimental method with ninhydrin for colouring honeydew droplets was used. Two experiments were conducted: The first one examined the honeydew production of small $M$. rosae populations of mixed developmental stages and the second experiment that of single adult aphids.

For the first trial, single leaflets from the apex of rose plant leaves (Kordana Classic 'Apache') were detached and placed with the petioles into tubes filled with tap water. The experiment was conducted in a climate chamber $\left(22 \pm 2{ }^{\circ} \mathrm{C}\right.$, $60 \pm 10 \%$ RH, 16:8 L:D). 30 aphids from the $M$. rosae culture were transferred with a fine brush to the lower side of each leaf. Five adult aphids, 10 third-fourth instar nymphs and 15 first-second nymphs were selected from the culture to have similar initial conditions for each population. Stems of the leaves were fixed with parafilm to avoid a turn of the leaf and leakage of water. The tubes were laid down on the seam of a Petri dish ( $85 \mathrm{~mm}$ diameter) underneath the leaf to ensure that the leaf is in horizontally position. The aphids were allowed to settle overnight. Next day, a filter paper ( $85 \mathrm{~mm}$ diameter) was placed in the Petri dish under each leaf. The filter paper was removed after $2 \mathrm{~h}$ and the upper side of the leaf was sprayed with the insecticide with $100 \mathrm{ml}$ handheld trigger bottles. Only the upper side was treated to avoid that aphids fell down due to the application and to minimize contact effects by the oily formulation. The following treatments were compared: an untreated control, $3.3 \mathrm{ml} / \mathrm{l}$ NeemAzal-T/S Blank, 1.65, 2.5 and $3.3 \mathrm{ml} / \mathrm{l}$ NeemAzal-T/S and $1.67 \mathrm{ml} / 1$ Flupyradifurone SL 50 as positive control. Per treatment, five leaves were sprayed. After application, a new filter paper was placed under the leaves for $2 \mathrm{~h}$. Then, new filter papers were placed in the Petri dishes for $24 \mathrm{~h}$ and were replaced two times. Thus, the honeydew was collected on the filter papers for $2 \mathrm{~h}$ before the application, $2 \mathrm{~h}$ and 1, 2 and 3 days after application. Additionally, the numbers of aphids per leaf were counted directly after removing the filter paper. After the experiment, the filter papers were sprayed with a $0.1 \%$ ninhydrin-acetone solution and allowed to dry. Ninhydrin coloured the honeydew droplets purple. After the experiments, all filter papers were photographed individually on a black background with a camera in the same position and settings. The size of the photos was $6000 \times 4000$ pixels. The photos were analysed individually for the amount of purple coloured pixels as a measurement of the area covered with honeydew with the image software Gimp, version
2.8.22 (The GIMP Development Team). Data were analysed for each time point as honeydew production per aphid by dividing the coloured area in pixels by the numbers of living aphids for each replication at each time point. The honeydew excretion during two hours before the application was set at $100 \%$ and the change in amount of honeydew was analysed. This method allows to take two important aspects into consideration: First, the natural honeydew production for each population individually before the application and second, the increase or decrease in numbers of aphids with time, e.g. mortality due to treatment effects. Some filter papers were dismissed from the analysis because of unclear colouring (purple water's edges on the filter papers). Due to the small number of replicates (maximum five, for some treatments and time points only four) and a non-normal distribution, no meaningful statistical analysis was possible.

For the second honeydew experiment with single adult aphids, pieces of filter paper $(2 \times 2 \mathrm{~cm})$ were saturated with a $0.1 \%$ ninhydrin-acetone solution before the experiment and allowed to dry for a day. For each treatment, six rose plants (Kordana Classic 'Flirt') were sprayed using a handheld sprayer. After drying of the plants, a clip cage with one adult rose aphid, randomly selected from the culture, was attached onto each plant. Underneath the clamped leaf with the aphid, one ninhydrin-treated filter paper piece was placed on the bottom of the clip cage and left there for $24 \mathrm{~h}$. Then, the filter paper was replaced by a new one. This was repeated twice for collecting the honeydew during 0-24, 24-48 and 48-72 $\mathrm{h}$ after application. Purple-coloured honeydew spots were counted on each filter paper the next day (time for colour development). Two similar trials were performed with this method. Per treatment and trial, six replications were used. One rose plant with a clip cage containing one adult aphid represents one replication. The following treatments were compared: an untreated control, $4.1 \mathrm{ml} / 1$ NeemAzalT/S Blank and 2.5, 3.3 and $4.1 \mathrm{ml} / 1 \mathrm{NeemAzal-T/S}$. The experiments took place in the greenhouse at $21 \pm 3{ }^{\circ} \mathrm{C}$, $60 \pm 10 \% \mathrm{RH}$ and a $16: 8 \mathrm{~L}: \mathrm{D}$ photoperiod.

For the statistical analysis, the data of the two experiments with each six replications were pooled, resulting in 12 replications per treatment. Cumulative honeydew production over time was assessed by summing of honeydew droplets. Influence of the treatments on the number of honeydew droplets was analysed with a GLM (Poisson distribution, log-link function) for each time period separately. Analysis was performed in SPSS (version 22, IBM).

\section{Feeding activity: electrical penetration graph}

To assess the probing and feeding behaviour of $M$. rosae on untreated and NeemAzal-T/S-treated rose plants, an electrical penetration graph (EPG) experiment was performed. Potted miniature rose plants of the variety 
Table 1 Treatments used for EPG experiment

\begin{tabular}{lllll}
\hline No. & Treatment name & Product & Concentration & Application \\
\hline 1 & Control & (Untreated) & & Spray application on same day as EPG \\
2 & Blank 3 & Blank formulation of NeemAzal-T/S & $3.3 \mathrm{ml} / \mathrm{l}$ & \\
3 & Blank 10 & Blank formulation of NeemAzal-T/S & $10 \mathrm{ml} / \mathrm{l}$ & \\
4 & NeemAzal-T/S 3 & NeemAzal-T/S & $3.3 \mathrm{ml} / \mathrm{l}$ & \\
5 & NeemAzal-T/S 6 & NeemAzal-T/S & $6.6 \mathrm{ml} / 1$ & \\
6 & NeemAzal-T/S 10 & NeemAzal-T/S & $10 \mathrm{ml} / \mathrm{l}$ & Spray application 24 h before EPG \\
7 & NeemAzal-T/S 24 h & NeemAzal-T/S & $3.3 \mathrm{ml} / 1$ & Drenching with 50 ml of a 3.3 ml/1 \\
8 & NeemAzal-T/S Soil & NeemAzal-T/S & $3.3 \mathrm{ml} / \mathrm{l}$ & NeemAzal-T/S solution per plant \\
\hline
\end{tabular}

Kordana Classic 'Sunstar' were used. An overview of the treatments of rose plants for the EPG recordings is given in Table 1. Plants were usually treated in the morning by spraying the solutions with a handheld trigger spraying bottle until a complete coverage was reached. Application was made on the day of recording (treatments 2-6) or one day earlier in the case of the treatments 7 and 8 .

For the EPG set-up, a fine golden wire was attached with silver glue to the abdomen of wingless, randomly selected adult $M$. rosae of unknown age. The golden wire was connected with an electrode and was included in an electrical circuit with another electrode in the soil of the rose plant. Directly after wiring, two DC-EPG devices (Giga-8, EPG Systems, Wageningen, The Netherlands) were used for recording of probing and feeding behaviour for $8 \mathrm{~h}$. Each device was used for a separate plant treatment and recordings of all treatments were randomized over the experimental period of three weeks. EPG signals of 15 aphids were recorded simultaneously per day. Each wired aphid was placed on a young, nearly completely developed leaf. This leaf was fixed upside down with tape on a plastic bar to prevent aphids from contact loss due to leaf movement. The software Stylet $+\mathrm{d}$, version 01.28 (EPG Systems, Wageningen, The Netherlands), was used to monitor and record the EPG waveforms.

Analysis of recorded EPG waveforms was done with the software Stylet + a, version 01.30 (EPG Systems, Wageningen, The Netherlands). Recordings with complete hours of no activity/no signals, unclear potential drops, or obviously escaped aphids were discarded. Table 2 presents the waveforms that were distinguished in the EPG analysis. For details of the EPG (DC) method and the analysed waveforms, see Tjallingii (1978, 1988, 1990, 1994), Van Helden and Tjallingii (2000) and Reese et al. (2000). Statistical analysis of numbers of probes and phases and the time spent in the different phases were compared with a Kruskal-Wallis test and if significant $(P<0.05)$, all pairwise comparisons were made with the Bonferroni-Dunn correction for multiple testing. The
Table 2 EPG waveforms that were differentiated and their biological meaning

\begin{tabular}{ll}
\hline Abbreviation & Biological meaning \\
\hline NP & Non-penetration period/no activity \\
pd & Potential drop/cell puncture \\
C & Stylet pathway including pd \\
E1 & Salivation in phloem \\
E2 & Ingestion of phloem \\
E & Phloem phase (E1 and E2) \\
G & Xylem ingestion \\
F & Penetration difficulties/mistakes \\
\hline
\end{tabular}

For detailed explanation of the terms, see Van Helden and Tjallingii (2000) and Reese et al. (2000)

software SPSS version 22 (IBM) was used for the statistical analysis.

\section{Results}

\section{Systemic effect of NeemAzal-T/S}

In both trials, systemic effects of a NeemAzal-T/S treatment were recorded on aphids placed on untreated plant parts. Mortality of $M$. rosae that were present on leaves that were not directly treated was higher than on control untreated plants for all tested concentrations of NeemAzalT/S and for both positions of the clip cages: higher than the treated plant parts (acropetal translocation, Fig. 2 panels $1 \mathrm{~A}$ and 2A; Table 3) and lower than the sprayed plant half (basipetal translocation, Fig. 2, panels $1 \mathrm{~B}$ and 2B). Mortality in the NeemAzal-T/S Blank treatments was similar as in the untreated control (Table 3). The hazard of mortality for $M$. rosae increases with increasing concentrations of NeemAzal-T/S in all cases. However, the lowest tested concentration, $1.65 \mathrm{ml} / \mathrm{l} \mathrm{NeemAzal-T/S}$, did not lead 
Fig. 2 Systemic effects of NeemAzal-T/S in rose plants in trial 1 (panels $1 \mathrm{~A}$ and $1 \mathrm{~B}$ ) and trial 2 (panels 2A and 2B). A Percentage survival of $M$. rosae nymphs on untreated plant parts higher than the sprayed part (acropetal translocation). B Percentage survival of $M$. rosae nymphs on untreated plant parts below the sprayed part (basipetal translocation). $N=5$ rose plants per treatment and tested direction of translocation (panels A and B), each with one clip cage containing several aphids. Initial total number of aphids ranged from 51 to 58 aphids per treatment for panel $1 \mathrm{~A}$ and from 51 to 59 aphids per treatment for panel $1 \mathrm{~B}$ in trial 1 . In trial 2 , initial total number of aphids ranged from 60 to 63 aphids per treatment for panel $2 \mathrm{~A}$ and from 58 to 63 aphids per treatment for panel $2 \mathrm{~B}$
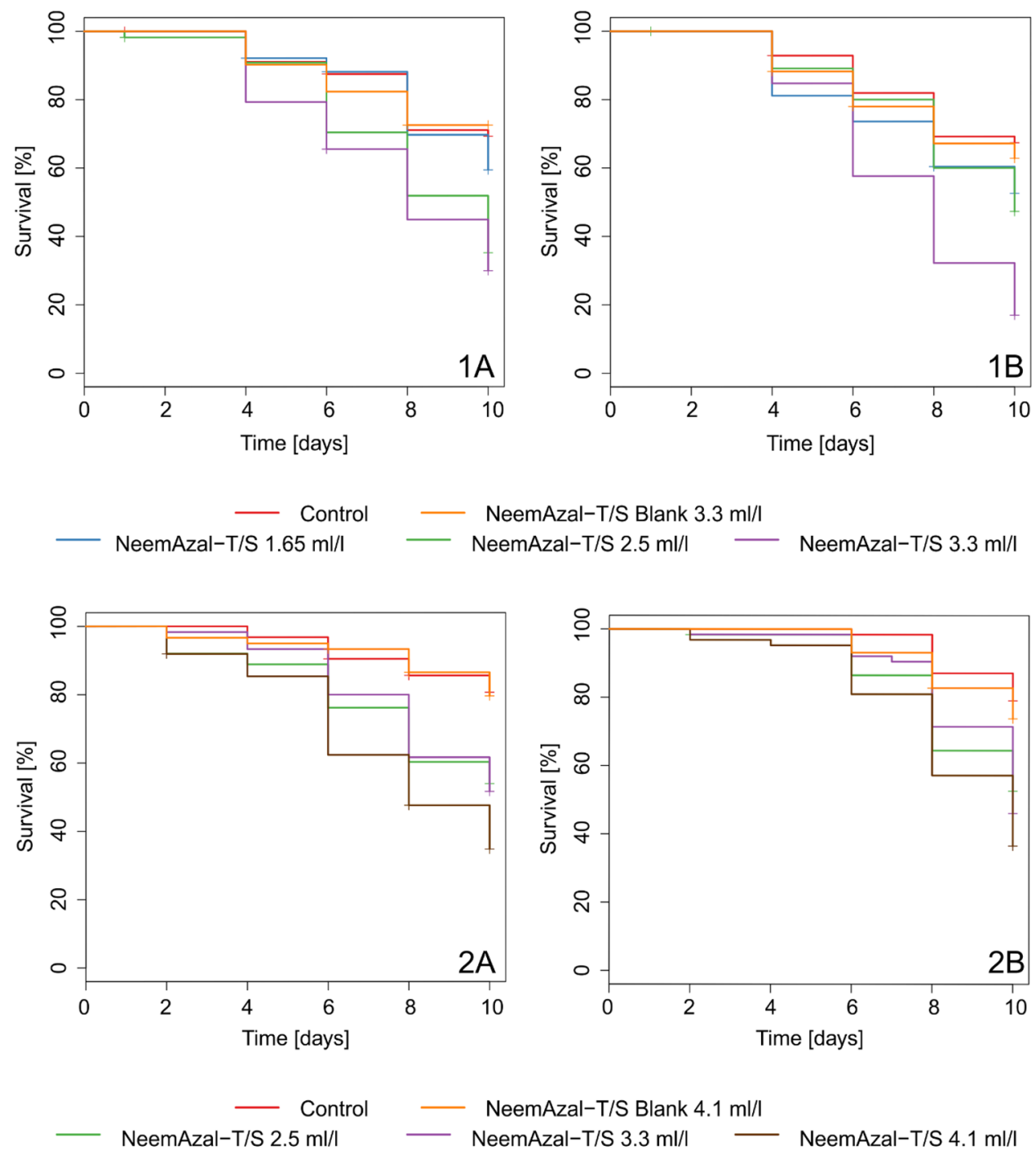

to a significantly higher mortality risk of $M$. rosae compared to the control (Table 3). With $3.3 \mathrm{ml} / 1$ NeemAzal$\mathrm{T} / \mathrm{S}$, a significantly higher mortality was recorded in both trials and for both tested directions of translocation. The hazard in the control group is set to 1 as the baseline hazard, while the hazard to die is significantly increased for M. rosae with the $3.3 \mathrm{ml} / 1$ and $4.1 \mathrm{ml} / 1 \mathrm{NeemAzal-T/S}$ treatment (Table 3).

\section{Repellent effects}

Nearly all released apterous $M$. rosae settled on the rose plants in the test arenas during the experimental period. Both treatment and time are important in predicting the number of aphids on plants $\left(\chi^{2}=10.19, \mathrm{df}=2, P=0.006\right.$ and $\chi^{2}=18.91$, $\mathrm{df}=5, P=0.002$, resp) whereas the change over time is similar for both treatments because there is no significant interaction effect $\left(\chi^{2}=1.27, \mathrm{df}=4, P=0.866\right)$. We did not find any significant post hoc differences among treatments at any of the time points (Fig. 3). The most informative time point is $72 \mathrm{~h}$, when almost all aphids had settled on one of the plants and at this time point, the numbers did not differ between treatments (Tukey adjusted $P=0.304$ ). These data indicate that NeemAzal-T/S does not repel M. rosae.

\section{Feeding activity: honeydew}

The honeydew excretion of $M$. rosae populations on untreated and treated rose leaflets during two hours before the application was set at $100 \%$. The honeydew excretion rate per living aphid up to three days is similar in all treatments including the control, with the exception of Flupyradifurone. In this treatment, the numbers of aphids decreased and also the honeydew excretion per living aphid approaches $0 \%$ at one day after application (Fig. 4).

For aphids that were individually present on a leaf, the cumulative numbers of honeydew droplets increase with 
Table 3 Effects of systemic treatments with NeemAzal$\mathrm{T} / \mathrm{S}$ on the mortality of $M$. rosae, presented as the mean hazard ratios (HR) to die in the different treatments according to Cox proportional hazards model
Fig. 3 Host-plant preference of M. rosae. Mean number $( \pm \mathrm{SE})$ of adult $M$. rosae on untreated rose plants and plants treated with $3.3 \mathrm{ml} / 1 \mathrm{NeemAzal}-\mathrm{T} / \mathrm{S}$ at $1,2,5,24$ and $72 \mathrm{~h}$ after release of 10 aphids in each test arena. $N=5$ test arenas, each with 10 released aphids. Data for nonsettled aphids are not shown. n.s.: non-significant (Tukey adjusted $P>0.05$ ) differences between the number of aphids on treatment vs. control groups within one time point based on GLMM (Poisson, log-link) with time and treatment as categorical variables and including the cage identity to account for repeated measurements

\begin{tabular}{|c|c|c|c|c|c|c|c|c|}
\hline \multirow[t]{3}{*}{ Treatment } & \multicolumn{4}{|c|}{ Acropetal } & \multicolumn{4}{|c|}{ Basipetal } \\
\hline & \multicolumn{2}{|c|}{ Trial 1} & \multicolumn{2}{|l|}{ Trial 2} & \multicolumn{2}{|c|}{ Trial 1} & \multicolumn{2}{|l|}{ Trial 2} \\
\hline & $\mathrm{HR}^{\mathrm{a}}$ & $P^{\mathrm{b}}$ & $\mathrm{HR}^{\mathrm{a}}$ & $P^{\mathrm{b}}$ & $\mathrm{HR}^{\mathrm{a}}$ & $P^{\mathrm{b}}$ & $\overline{\mathrm{HR}^{\mathrm{a}}}$ & $P^{\mathrm{b}}$ \\
\hline Control & $1^{\mathrm{c} b}$ & & $1^{\mathrm{c}}$ & & $1^{\mathrm{c} b}$ & & $1^{\mathrm{c} b c}$ & \\
\hline NeemAzal-T/S Blank ${ }^{\mathrm{d}}$ & $1.0 \mathrm{~b}$ & 0.94 & $1.0 \mathrm{bc}$ & 0.93 & $1.2 \mathrm{~b}$ & 0.71 & $1.3 \mathrm{c}$ & 0.53 \\
\hline NeemAzal-T/S $1.65 \mathrm{ml} / 1$ & $1.5 b$ & 0.37 & - & - & $1.6 a b$ & 0.27 & - & - \\
\hline NeemAzal-T/S $2.5 \mathrm{ml} / \mathrm{l}$ & $2.1 \mathrm{ab}$ & $0.008 *$ & $2.9 \mathrm{abc}$ & $0.023^{*}$ & $1.8 \mathrm{ab}$ & 0.20 & $2.9 \mathrm{abc}$ & 0.06 \\
\hline NeemAzal-T/S 3.3 ml/l & $3.6 \mathrm{a}$ & $0.001 *$ & $3.0 \mathrm{ab}$ & $0.003^{*}$ & $3.8 \mathrm{a}$ & $<0.001 *$ & $3.1 \mathrm{ab}$ & $0.020 *$ \\
\hline NeemAzal-T/S $4.1 \mathrm{ml} / 1$ & - & - & $4.9 \mathrm{a}$ & $<0.001 *$ & - & - & $4.3 \mathrm{a}$ & $0.004 *$ \\
\hline
\end{tabular}

Acropetal translocation effects were tested with clip cages attached onto leaves above the treated plant parts. Basipetal translocation effects were tested with clip cages attached on leaves below treated plant parts. Control groups functioned as baseline hazards. $N=5$ rose plants, each with one clip cage, per treatment and tested direction (acropetal and basipetal), for each experiment. Every clip cage contained 6 to $14 \mathrm{M}$. rosae nymphs at the start of the experiment. Aphid mortality was assessed for 10 days

${ }^{a} \mathrm{HR}$ : hazard ratio. Different letters within the same column indicate significant $(P<0.05)$ differences in HR according to Tukey post hoc all-pair comparison in the Cox proportional hazards model

${ }^{\mathrm{b}} P$-value represents the significance of the influence of the treatment on the mortality for $M$. rosae according to Cox proportional hazard model with "Control" as baseline hazard. Significant $P$ values are marked with an asterisk

${ }^{c} \mathrm{HR}$ for control set to 1 as baseline hazard

${ }^{\mathrm{d}}$ NeemAzal-T/S Blank was applied with $3.3 \mathrm{ml} / \mathrm{l}$ in experiment 1 and with $4.1 \mathrm{ml} / \mathrm{l}$ in experiment 2

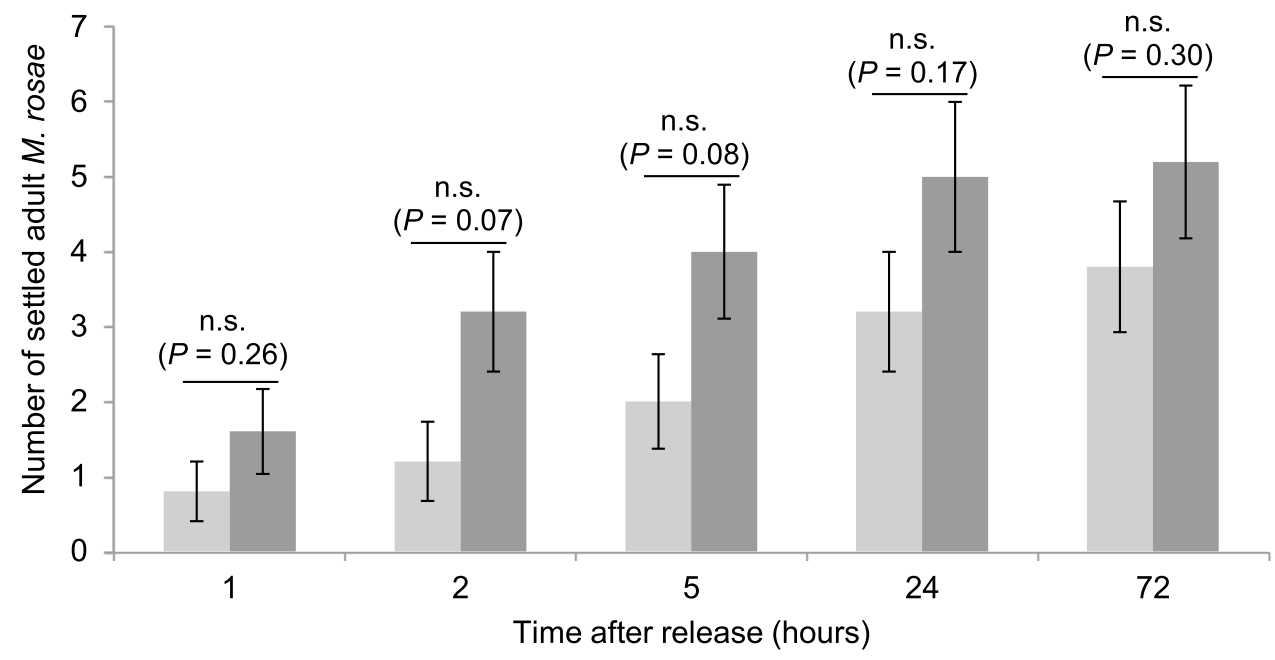

Untreated NeemAzal-T/S time. Aphids excreted approximately one droplet per day in all treatments. We found no significant differences in the number of honeydew droplets secreted by adult M. rosae on untreated plants and plants treated with different concentrations of NeemAzal-T/S or the blank formulation (Fig. 5).

\section{Feeding activity: electrical penetration graph (EPG) analysis}

EPG recordings of 16 to 22 aphids per treatment were analysed for the complete recording time of $8 \mathrm{~h}$. From the
EPG recordings, parameters regarding no activity (NP), pathway with probing punctures $(\mathrm{C} / \mathrm{pd})$ and phloem ingestion $(\mathrm{E})$ were analysed as well as xylem-ingestion $(\mathrm{G})$ and penetration difficulties $(F)$. For most parameters, the number of periods as well as the total duration was compared between treatments.

In the untreated control, aphids had significantly $(P<0.05)$ lower numbers of probes in $8 \mathrm{~h}$ compared to the soil treatment of NeemAzal-T/S (NeemAzal-T/S Soil) (Table 4). No differences were found for numbers and/or duration of no activity periods (NP), total time of pathway 
Fig. 4 Mean honeydew excretion $( \pm \mathrm{SE})$ per hour and per individual living $M$. rosae aphid before and 1, 2 and 3 days after application as percentage of honeydew excretion in the control group $(=100 \%)$, assessed as honeydew covered area in pixels of small populations. Total covered area of each replication was divided by the number of living aphids in that replication for each assessment time to exclude mortality effects. $N=4$ to 5 observed $M$. rosae populations on single excised leaves per treatment at each time point with varying numbers of aphids of different developmental stages

Fig. 5 Honeydew secretion by individual adult $M$. rosae as mean $( \pm$ SE) cumulative number of droplets per aphid over 3 days after application of NeemAzal-T/S and the blank formulation. $N=12$ aphids per treatment (pooled data of two replicate experiments, each with 6 observed aphids per treatment). n.s. $=$ not significant $(P>0.05)$ influence of treatment on number of honeydew droplets per aphid according to GLM (Poisson, log-link) for each time point
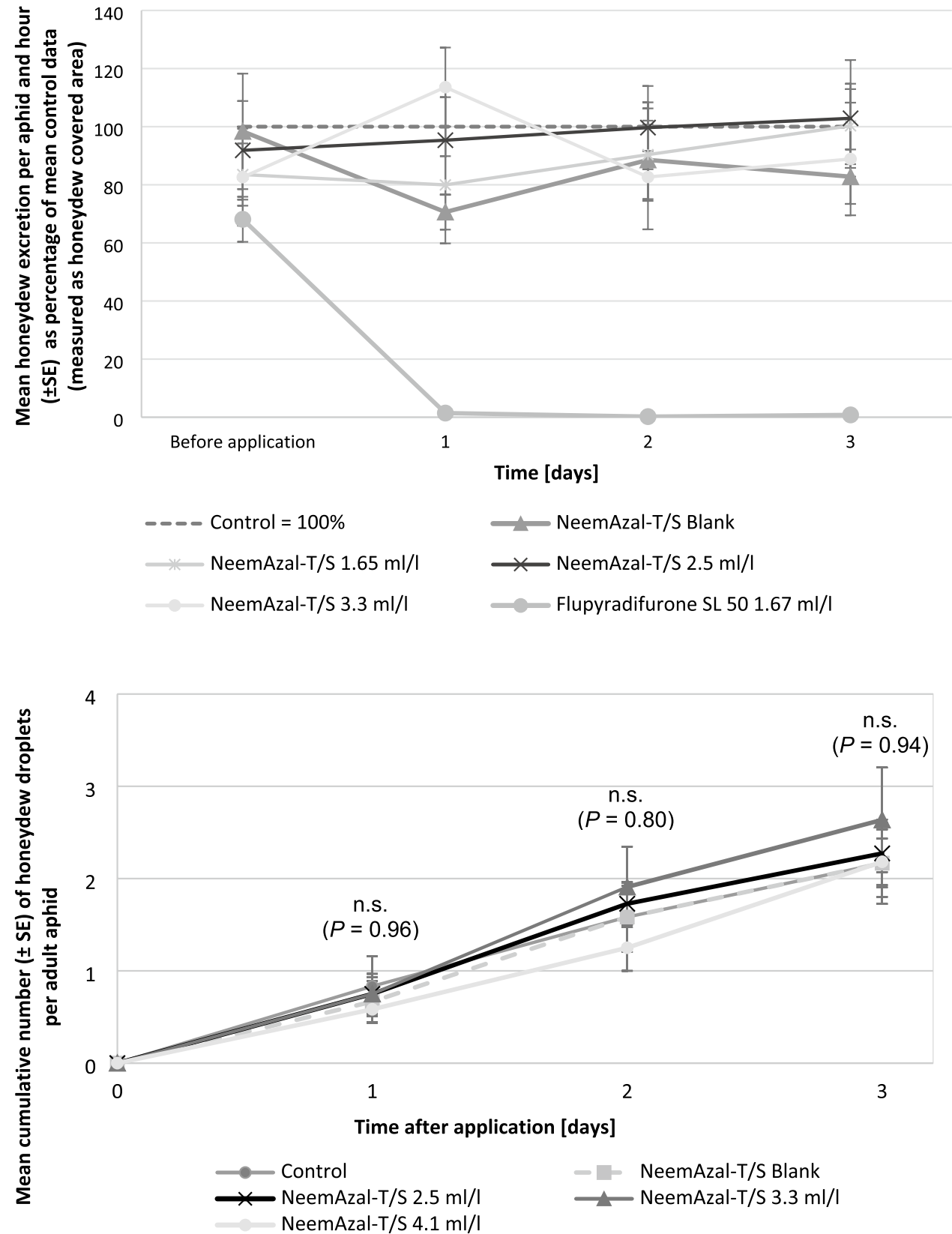

phases (C/pd) (Table 4), numbers and duration of xylemingestion periods $(\mathrm{G})$ or for periods with penetration difficulties (F). Patterns $G$ and $F$ were only recorded occasionally and not in all recordings (Supplement Table 5).

For the comparison of phloem salivation and ingestion, the total duration of E1 (phloem salivation) and E2 (phloem ingestion) was included in the analysis, as well as the total duration of phloem phases. No significant differences were found for any of these parameters between the treatments (Supplement Table 6). Total duration of phloem phases includes E1, E2 and unknown phloem waveforms. These unknown waveforms were found in some recordings (Supplement Table 7; Fig. 6), but number and duration of these patterns did not significantly differ between treatments and have not been analysed in further detail. Additionally to these parameters, the time to the first E2 phase was analysed as well as the time to the first sustained phloem phase and total duration of sustained E2. Sustained phloem phase is inferred from the E2 phase lasting longer than $10 \mathrm{~min}$. An E2 phase longer than 10 min lasts in most cases longer than $1 \mathrm{~h}$ (Tjallingii 1994) and this time can be used as the threshold time for the acceptance of a sieve element by aphids (Tjallingii 1990, 1994, 2006). No significant differences were found for these parameters. Additionally, no correlation with increasing concentrations of NeemAzal-T/S was found (Supplement Table 6). 
Table 4 EPG parameters (mean $\pm \mathrm{SE}$ ) of $M$. rosae regarding probing, nonpenetration (NP) and pathway periods $(\mathrm{C})$ on untreated (control) rose plants and plants treated with different concentrations of NeemAzalT/S Blank or NeemAzal-T/S

\begin{tabular}{llllll}
\hline Treatment & $N$ & No. probes in $8 \mathrm{~h}$ & No. NP periods & $\begin{array}{l}\text { Total duration } \\
\text { NP (minutes) }\end{array}$ & $\begin{array}{l}\text { Total duration of C } \\
\text { including pd (min- } \\
\text { utes) }\end{array}$ \\
\hline Control & 22 & $130.6 \pm 20.9 \mathrm{~b}$ & $11.5 \pm 1.9 \mathrm{a}$ & $45.2 \pm 11.5 \mathrm{a}$ & $125.7 \pm 20.4 \mathrm{a}$ \\
NeemAzal-T/S Blank 3 & 19 & $183.8 \pm 24.1 \mathrm{ab}$ & $16.5 \pm 3.1 \mathrm{a}$ & $49.6 \pm 15.2 \mathrm{a}$ & $159.8 \pm 19.9 \mathrm{a}$ \\
NeemAzal-T/S Blank 10 & 22 & $193.5 \pm 21.7 \mathrm{ab}$ & $13.2 \pm 3.9 \mathrm{a}$ & $37.4 \pm 9.2 \mathrm{a}$ & $166.0 \pm 17.5 \mathrm{a}$ \\
NeemAzal-T/S 3 & 21 & $150.4 \pm 20.4 \mathrm{ab}$ & $16.5 \pm 3.8 \mathrm{a}$ & $53.1 \pm 15.9 \mathrm{a}$ & $121.5 \pm 16.0 \mathrm{a}$ \\
NeemAzal-T/S 6 & 16 & $202.8 \pm 25.5 \mathrm{ab}$ & $18.8 \pm 3.0 \mathrm{a}$ & $64.8 \pm 12.2 \mathrm{a}$ & $165.5 \pm 18.1 \mathrm{a}$ \\
NeemAzal-T/S 10 & 21 & $158.1 \pm 17.3 \mathrm{ab}$ & $11.0 \pm 3.2 \mathrm{a}$ & $38.4 \pm 10.8 \mathrm{a}$ & $141.2 \pm 16.0 \mathrm{a}$ \\
NeemAzal-T/S 24 h & 20 & $175.9 \pm 22.3 \mathrm{ab}$ & $13.8 \pm 2.4 \mathrm{a}$ & $41.0 \pm 8.3 \mathrm{a}$ & $139.6 \pm 18.5 \mathrm{a}$ \\
NeemAzal-T/S Soil & 19 & $227.8 \pm 25.3 \mathrm{a}$ & $18.9 \pm 3.7 \mathrm{a}$ & $59.8 \pm 17.5 \mathrm{a}$ & $193.2 \pm 19.8 \mathrm{a}$ \\
\hline
\end{tabular}

See Table 1 for an overview of the different treatments. Different letters within the same column indicate significant $(P<0.05)$ differences in means based on a Kruskal-Wallis Test and a Bonferroni-corrected post hoc all-pair comparison

$N$ total number of replicates (recordings of single aphids analysed for each treatment)

$N P$ non-penetration time/no activity

$C / p d$ Stylet pathway including probes $(\mathrm{pd}=$ potential drops)
On average, the first sustained E2 phase (phloem ingestion longer than $10 \mathrm{~min}$ ) began after $107 \mathrm{~min}$ (NeemAzal$\mathrm{T} / \mathrm{S} \mathrm{3}$ ) up to $230 \mathrm{~min}$ (NeemAzal-T/S 6). For this reason, the analysis of recordings was conducted separately for hours 1 to 4 and 5 to 8 . The aim was to assess possible treatment effects after aphids had obtained the first phloem sap ingestion (sustained E2) in the second time period of 5 to $8 \mathrm{~h}$. However, no significant differences were found between the treatments in both time periods for number of probes, duration of no activity (NP), pathway period $(\mathrm{C} / \mathrm{pd})$ and the phloem phases (E, E1, E2, sustained E2). Furthermore, no pattern is visible with increasing concentrations of NeemAzal-T/S (Supplement Tables 8-10).

\section{Discussion}

The present study shows that local treatment of rose plants with NeemAzal-T/S has systemic effects on mortality of $M$. rosae nymphs. NeemAzal-T/S did not repel M. rosae adults or interfere with their feeding activity, as assessed by quantification of honeydew production and EPG recording. Our results indicate that the effect of NeemAzal-T/S on M. rosae is based on toxic effects after ingestion of azadirachtin-containing phloem sap and not a consequence of lower food intake or starvation.

\section{Systemic action}

The first objective of our study was to examine the systemic effect of NeemAzal-T/S. Systemic effects of insecticides are a benefit and usually enhance the potential for an efficient insect control, because hidden individuals will be affected and newly growing shoots will be protected. Our results show that $M$. rosae nymphs exhibited a significantly higher mortality when they fed on untreated plant parts both above and below the plant part which was sprayed with the neem product. These results indicate that active ingredients of NeemAzal-T/S are translocated systemically, acropetally as well as basipetally. An acropetal uptake and translocation of azadirachtin and other toxins from neem were expected and reported before (e.g. Sundaram et al. 1995; Thoeming et al. 2003, 2006; Pavela et al. 2004; Kumar et al. 2005). However, in previous studies, the systemic effect usually followed a soil or root treatment. A spread of active ingredients from other aboveground plant parts, e.g. from treated leaves to untreated leaves, has only been reported for chrysanthemum so far. In chrysanthemum plants, spraying the upper or lower half of the plants with a neem extract equivalent to $23 \mathrm{ppm}$ azadirachtin slightly reduced the numbers of pupae and adults of a leaf mining dipteran pest (Liriomyza trifolii) on the untreated plant half. However, the translocated amounts of neem extract did not effectively control the leaf miner that feeds on mesophyll cells (Larew 1988). The translocation or presence of azadirachtin or other neem toxins in the phloem is generally regarded as low (Larew 1988; Schmutterer 1988; National Research Council 1992). A basipetal translocation and the spread from treated leaves to higher plant parts indicate that toxins from neem extracts are not only distributed in the xylem of plants, but most likely also in the phloem. In our study, after applying NeemAzal-T/S in common doses, the active ingredients seem to be sufficiently distributed in rose plants to control $M$. rosae nymphs not only on treated but also on untreated plant parts. Although the concentration of compounds in untreated plant parts was not analysed directly, our results of a bilateral translocation are important for the control of M. rosae and other aphids for two reasons. First, the data suggest that the insecticidal compounds are 
available in the phloem of rose plants after spraying. Second, newly growing shoot tips and buds, the preferred feeding sites of $M$. rosae, that developed after a neem treatment, will be protected as well. In general, the effectiveness of the translocation of azadirachtin and other active substances from neem might be significantly influenced by the plant and pest species (Larew 1988; Lowery et al. 1993; Lowery and Isman 1993, 1994a, 1994b).

\section{Repellent effect}

The second objective of our study was to investigate whether NeemAzal-T/S has repellent or antifeedant effects on $M$. rosae. Because the neem product does not have a direct effect on adults in terms of mortality or reproduction (Bartelsmeier et al. 2022), a repellent effect against adult stages would be advantageous for the protection of rose plants with neem. However, neither a repellent nor an antifeedant effect has been recorded in our experiments on apterous females of $M$. rosae.

Repellence was also not recorded for M. persicae on artificial diet treated with 25-100 ppm azadirachtin (Nisbet et al. 1994). In contrast, $50 \mathrm{ppm}$ and higher concentrations of azadirachtin sprayed on barley leaves repelled $S$. avenae and $R$. padi in the first $25 \mathrm{~min}$ after the start of exposure (West and Mordue 1992). Repellent effects only contribute to insect control if the effect is sustained-preferably for a few days at least to prevent aphid settling and population growth. In the case of M. rosae and rose plants, the common dose of NeemAzal-T/S, equivalent to $33 \mathrm{ppm}$ azadirachtin A, did not cause any repellent effect in our studies with adult aphids. Thus, aphids most likely did not leave treated plants to settle on untreated plants during the assessed 72-h period. Other instars might react differently. To deter second instar M. rosae, concentrations of a neem seed extract equivalent to only $11 \mathrm{ppm}$ azadirachtin were necessary to cause $50 \%$ deterrence. Initial observations showed that no repellent effect was present. 100\% deterrence was achieved with $100 \mathrm{ppm}$ azadirachtin after $6 \mathrm{~h}$ in a leaf disc study (Koul 1999). Experiments to assess the effect of commercial products such as NeemAzal-T/S in terms of repellence or deterrence of $M$. rosae nymphs remain to be done.

\section{Feeding activity: honeydew production}

Neither of the feeding tests, i.e. a quantitative method assessing the honeydew production and a qualitative method, EPG recording, revealed differences in feeding activity of $M$. rosae with increasing neem concentrations. No effects on honeydew production, a proxy for feeding intensity, were recorded in our experiments. Honeydew excretion was compared for small $M$. rosae populations of mixed developmental stages on detached leaves as well as for single adults.
Interestingly, Nisbet et al. (1994) determined that honeydew production of adult $M$. persicae was reduced during the exposure to azadirachtin-treated artificial diets after an initial period of $26 \mathrm{~h}$. During the first $26 \mathrm{~h}$, no differences were found, but in the subsequent period of $24 \mathrm{~h}$, honeydew production was significantly reduced compared to the control (Nisbet et al. 1994). Already 25 ppm azadirachtin had significant effects. The concentrations in our study ranged from 25 to $41 \mathrm{ppm}$ azadirachtin, but no effects on honeydew excretion of adult $M$. rosae were recorded. Different aphid species may respond differently (Lowery and Isman 1993, 1994a, 1994b), but a major difference was also the use of artificial diet versus plants as food source. Plants contain a variety of secondary metabolites that may interact with the effect of azadirachtin. Honeydew production of M. rosae populations was compared to aphids on rose leaves sprayed with the synthetic insecticide flupyradifurone. Flupyradifurone is known for its very strong antifeedant effects on aphids and a rapid decrease in honeydew production (Nauen et al. 2015). This effect of flupyradifurone was also remarkable in our study in contrast to the effect of NeemAzal-T/S which had no impact on honeydew production of M. rosae.

\section{Feeding activity: electrical penetration graph analysis}

Studying feeding activity through EPG recording resulted in only one significant difference: mean number of probes was significantly higher in the NeemAzal-T/S soil treatment compared to the control. However, no differences compared to the blank formulation treatments were recorded and there was no correlation with the dose applied. Based on our study, common doses of NeemAzal-T/S do not appear to affect the feeding of adult $M$. rosae. Only one other study has been published that investigated the effect of azadirachtin on phloem-feeding insects with the EPG technique. Nisbet (1992) studied whether probing and feeding by M. persicae are affected by root treatments of tobacco seedlings with high azadirachtin doses, i.e. 100 to $1000 \mathrm{ppm}$. Roots of tobacco seedlings were immersed in azadirachtin solutions $27 \mathrm{~h}$ before the EPG recordings. Apterous M. persicae displayed a higher percentage of total recording time expressing non-penetration and pathway periods at very high doses of at least 300 and 500 ppm azadirachtin. Furthermore, the aphids showed more phloem periods, but these were significantly shorter than in the control (Nisbet 1992; Nisbet et al. 1993). Interestingly, when a topical application was compared to a root treatment with $500 \mathrm{ppm}$ azadirachtin, significantly more time was spent on non-penetrating and pathway time in the root treatment, but not in the topical application (Nisbet 1992). Also in our experiment, soil application with $33 \mathrm{ppm}$ azadirachtin ( $3.3 \mathrm{ml} / 1 \mathrm{NeemAzal-T/S})$ led to significantly more probes. However, because no other EPG parameters 
differed, the impact of azadirachtin on feeding behaviour seems to be limited.

Phloem feeding by the leafhopper Nephotettix virescens on neem-oil-treated rice plants was significantly reduced. It is remarkable that the leaf hopper probed more, seemed restless and changed from phloem feeding to xylem feeding on treated rice plants (Saxena and Khan 1985). In our EPG experiment, however, xylem feeding by $M$. rosae rarely occurred and no differences between the treatments were found for this parameter.

In the EPG experiment, we tested NeemAzal-T/S as foliar applications in doses of $3.3,6.6$ and $10 \mathrm{ml} / 1$, equivalent to 33, 66 and $100 \mathrm{ppm}$ azadirachtin, and therefore exceeded the registered dose (30-50 ppm) already 2- to 3-fold with the highest concentration tested. Nevertheless, no effects of NeemAzal-T/S on feeding behaviour were found. Previous studies showed that very high concentrations of azadirachtin were effective. For absolute antifeedant and repellent effects, concentrations of 100 to $500 \mathrm{ppm}$ azadirachtin are recommended and activity only persists for a few days (Koul et al. 1997; Koul 1999; Nisbet 1992; Nisbet et al. 1993; West and Mordue 1992). Such concentrations are not allowed in today's practical use of neem products. Furthermore, effects differ remarkably between aphid species and ages (Lowery and Isman 1993; Koul 1999). Repellent and deterrent effects of insecticides in addition to mortality are advantageous, because the excretion of honeydew will be reduced as well as the transmission of aphid-transmitted plant viruses. However, according to our studies and previous work discussed above, repellent and deterrent effects of azadirachtin or neem formulations do not provide a main contribution to aphid control.

\section{Conclusion}

In conclusion, the bidirectional systemic effect of NeemAzal-T/S that was reported here benefits control of M. rosae, because it enhances aphid mortality. Moreover, the common application of spraying $3.3 \mathrm{ml} / 1$ NeemAzal$\mathrm{T} / \mathrm{S}$ does not influence the settling behaviour and feeding of $M$. rosae. A significant nymphal mortality is a typical effect of azadirachtin in aphids (e.g. Lowery and Isman 1994a; Koul 1999) and mainly contributes to an effective control. For the practical application of NeemAzal-T/S, insect growth-regulating (IGR) effects in immature aphids after feeding on treated plants and a reduced reproduction are the relevant effects for controlling rose aphids (Lowery and Isman 1993; Bartelsmeier et al. 2022). These IGR effects might allow a combination of azadirachtin products with biological control agents in integrated pest management (IPM) strategies to achieve good pest control levels. However, possible side effects to beneficial insects needs to be taken into consideration (Desneux et al. 2007), e.g. the active ingredient azadirachtin might be present in nectaries of treated plants or in the honeydew of treated aphids and thus in the energy source of many predators and parasitoids as found for other systemic active ingredients (Calvo-Agudo et al. 2019; Jones et al. 2020). Some studies support the possibility of combining azadirachtin products with beneficial arthropods or other biological control agents in IPM strategies (Medina et al. 2001; Otieno et al. 2017), also in roses (Put et al. 2016). Future research should address such combinations under greenhouse conditions to support growers in implementing smart and sustainable pest control programmes for aphids and other pests.

Supplementary Information The online version contains supplementary material available at https://doi.org/10.1007/s11829-022-09889-x.

Acknowledgements We would like to thank Dr. Edmund Hummel from Trifolio-M for providing the blank formulation of the tested product.

Author contributions IB, MK, CTB and MD conceived and designed the research. IB conducted the experiments, analysed the data, with DM, and wrote the manuscript with the input from MK, CTB, DM and MD. All authors approved the manuscript.

Funding This study was funded by Bayer AG, Crop Science Division.

Data availability Data are available on request.

\section{Declarations}

Conflict of interest All authors declare that they have no conflict of interest.

Open Access This article is licensed under a Creative Commons Attribution 4.0 International License, which permits use, sharing, adaptation, distribution and reproduction in any medium or format, as long as you give appropriate credit to the original author(s) and the source, provide a link to the Creative Commons licence, and indicate if changes were made. The images or other third party material in this article are included in the article's Creative Commons licence, unless indicated otherwise in a credit line to the material. If material is not included in the article's Creative Commons licence and your intended use is not permitted by statutory regulation or exceeds the permitted use, you will need to obtain permission directly from the copyright holder. To view a copy of this licence, visit http://creativecommons.org/licenses/by/4.0/.

\section{References}

Alford DV (2012a) Chapter 1: Introduction. In: Alford DV (ed) Pests of ornamental trees, shrubs and flowers, A color handbook, 2nd edn. Manson Publishing Ltd, London, pp 9-19

Alford DV (2012b) Chapter 2: Insects. Macrosiphum rosae (Linnaeus). In: Alford DV (ed) Pests of ornamental trees, shrubs and flowers, A color handbook, 2nd edn. Manson Publishing Ltd, London, pp 66-67 
Bartelsmeier I, Kilian M, Dicke M (2022) Effects of NeemAzal-T/S on different developmental stages of rose aphid, Macrosiphum rosae. Exp Appl Entomol. https://doi.org/10.1111/eea.13141

Boeke SJ, Biersman MG, Alink GM, van Loon JJA, van Huis A, Dicke M, Rietjens IMCM (2004) Safety evaluation of neem (Azadirachta indica) derived pesticides. J Ethnopharmacol 94:25-41. https:// doi.org/10.1016/j.jep.2004.05.011

Brødsgaard HF, Albajes R (1999) Chapter 4: Insect and mite pests. In: Albajes R, Gullino ML, van Lenteren JC, Elad Y (eds) Integrated pest and disease management in greenhouse crops. Kluwer Academic Publishers, Dordrecht, pp 48-60

Brooks ME, Kristensen K, Van Benthem KJ, Magnusson A, Berg CW, Nielsen A, Skaug HJ, Machler M, Bolker BM (2017) glmmTMB balances speed and flexibility among packages for zero-inflated generalized linear mixed modeling. R J 9(2):378-400

Calvo-Agudo M, González-Cabrera J, Picó Y, Calatyud-Vernich P, Urbaneja A, Dicke M, Tena A (2019) Neonicotinoids in excretion product of phloem-feeding insects kill beneficial insects. Proc Natl Acad Sci USA 116:16817-16822. https://doi.org/10. 1073/pnas. 1904298116

Desneux N, Decourtye A, Delpuech JM (2007) The sublethal effects of pesticides on beneficial arthropods. Annu Rev Entomol 52:81-106. https://doi.org/10.1146/annurev.ento.52.110405. 091440

Feng R, Isman MB (1995) Selection for resistance to azadirachtin in the green peach aphid, Myzus persicae. Experientia 51:831-833. https://doi.org/10.1007/BF01922438

German Federal Office of Consumer Protection and Food Safety (BVL) (2017) Entry for NeemAzal-T/S, registration in ornamental plants, application no. 024436-00/00-009, 024436-00/00-010, 02443600/00-011, 024436-00/00-012 and 024436-00/00-013. Available under the entry for "NeemAzal-T/S" in the BVL database for plant protection products. https://www.bvl.bund.de/EN/04_PlantProte ctionProducts/01_ppp_tasks/02_ppp_AuthorisationReviewA ctSub/01_\%20ppps_authorised/01_ppp_online_database/ppp_ online_database_node.html. Accessed 12 Dec 2017

Hothorn T, Bretz F, Westfall P (2008) Simultaneous inference in general parametric models. Biom J 50:346-363. https://doi.org/10. 1002/bimj.200810425

Hunter WB, Ullmann DE (1992) Effects of the neem product, RDRepelin, on settling behavior and transmission of zucchini yellow mosaic virus by the pea aphid, Acyrthosiphum pisum (Harris) (Homoptera: Aphididae). Ann Appl Biol 120:9-15. https://doi. org/10.1111/j.1744-7348.1992.tb03398.x

Isman MB, Koul O, Luczynski A, Kaminski J (1990) Insecticidal and antifeedant bioactivities of neem oils and their relationship to azadirachtin content. J Agric Food Chem 38:1406-1411. https:// doi.org/10.1021/jf00096a024

Jones AG, Hoover K, Pearsons K, Tooker JF, Felton GW (2020) Potential impacts of translocation of neonicotinoid insecticides to cotton (Gossypium hirsutum (Malvales: Malvaceae)) extrafloral nectar on parasitoids. Environ Entomol 49:159-168. https://doi.org/10. 1093/ee/nvz157

Karanja J, Poehling HM, Pallmann P (2015) Efficacy and dose response of soil-applied neem formulations in substrates with different amounts of organic matter, in the control of whiteflies, Aleyrodes proletella and Trialeurodes vaporariorum (Hemiptera: Aleyrodidae). J Econ Entomol 108:1182-1190. https://doi.org/10.1093/ jee/tov047

Koul O (1999) Insect growth regulating and antifeedant effects of neem extracts and azadirachtin on two aphid species of ornamental plants. J Biosci 24:85-90. https://doi.org/10.1007/BF02941111

Koul O, Shankar JS, Mehta N (1997) Antifeedant activity of neem seed extracts and azadirachtin to cabbage aphid, Brevicoryne brassicae (L.). Indian J Exp Biol 35:994-997
Kraus W (1995) Biologically active ingredients: Azadirachtin and other triterpenoids. In: Schmutterer H (ed) The neem tree Azadirachta Indica A. Juss and other meliaceous plants. $\mathrm{VCH}$, Weinheim, pp 35-74

Kumar P, Poehling HM, Borgemeister C (2005) Effects of different application methods of azadirachtin against sweetpotato whitefly Bemisia tabaci ennadius (Hom., Aleyrodidae) on tomato plants. J Appl Entomol 129:489-497. https://doi.org/10.1111/j.1439-0418. 2005.01009.x

Larew HG (1988) Limited occurrence of foliar-, root-, and seed-applied neem seed extract toxin in untreated plant parts. J Econ Entomol 81:593-598. https://doi.org/10.1093/jee/81.2.593

Ley SV, Denholm AA, Wood A (1993) The chemistry of azadirachtin. Nat Prod Rep 10:109-157

Lowery DT, Isman MB (1993) Antifeedant activity of extracts from neem, Azadirachta indica, to strawberry aphid, Chaetosiphon fragaefolii. J Chem Ecol 19:1761-1773. https://doi.org/10.1007/ BF00982306

Lowery DT, Isman MB (1994a) Insect growth regulating effects of neem extracts and azadirachtin on aphids. Entomol Exp Appl 72:77-84. https://doi.org/10.1111/j.1570-7458.1994.tb01804.x

Lowery DT, Isman MB (1994b) Chapter 7. Effects of neem and azadirachtin on aphids and their natural enemies. In: Hedin P (ed) Bioregulators for crop protection and pest control. ACS Symposium Series, American Chemical Society, Washington, DC, USA, pp 78-91

Lowery DT, Isman MB, Brard NL (1993) Laboratory and field evaluation of neem for the control of aphids (Homoptera: Aphididae). J Econ Entomol 86:864-870. https://doi.org/10.1093/jee/86.3.864

Maelzer DA (1977) The biology and main causes of changes in numbers of the rose aphid, Macrosiphum rosae (L.), on cultivated roses in South Australia. Aust J Zool 25:269-284. https://doi.org/ 10.1071/ZO9770269

Medina P, Budia F, Tirry L, Smagghe G, Vinuela E (2001) Compatibility of spinosad, tebufenozide and azadirachtin with eggs and pupae of the predator Chrysoperla carnea (Stephens) under laboratory conditions. Biocontrol Sci Technol 11:597-610. https://doi. org/10.1080/09583150120076157

Meier U, Bleiholder H, Brumme H, Bruns E, Mehring B, Proll T, Wiegand J (2009) Phenological growth stages of roses (Rosa sp.): codification and description according to the BBCH scale. Ann Appl Biol 154:231-238. https://doi.org/10.1111/j.1744-7348. 2008.00287.x

Mordue AJ, Blackwell A (1993) Azadirachtin: an update. J Insect Physiol 33:903-924. https://doi.org/10.1016/0022-1910(93)90001-8

Mordue AJ, Nisbet AJ (2000) Azadirachtin from the neem tree Azadirachta indica: its action against insects. An Soc Ent Bras 29:615-632

Mordue AJ, Morgan ED, Nisbet AJ (2010) 5: Azadirachtin, a natural product in insect control. In: Gilbert LI, Gill SS (eds) Insect control. Biological and synthetic agents. Elsevier B. V, Amsterdam, pp 185-206

Morgan ED (2009) Azadirachtin, a scientific gold mine. Bioorg Med Chem 17:4096-4105. https://doi.org/10.1016/j.bmc.2008.11.081

National Research Council (1992) Chapter 4: What's in a neem. In: Ruskin FR (ed) Neem: a tree for solving global problems. National Research Council, The National Academy Press, Washington DC, pp 31-38

Nauen R, Jeschke P, Velten R, Beck ME, Ebbinghaus-Kintscher U, Thielert W, Wölfel K, Haas M, Kunz K, Raupach G (2015) Flupyradifurone: a brief profile of a new butenolide insecticide. Pest Manag Sci 71:850-862. https://doi.org/10.1002/ps.3932

Nisbet AJ (1992) The effects of azadirachtin on the feeding behaviour and virus transmission of the green peach aphid, Myzus persicae (Sulzer). Dissertation, University of Glasgow 
Nisbet AJ, Woodford JAT, Strang RHC, Connolly JD (1993) Systemic antifeedant effects of azadirachtin on the peach-potato aphid Myzus persicae. Entomol Exp Appl 68:87-98. https://doi.org/10. 1111/j.1570-7458.1993.tb01692.x

Nisbet AJ, Woodford JAT, Strang RHC (1994) The effects of azadirachtin-treated diets on the feeding behaviour and fecundity of the peach-potato aphid, Myzus persicae. Entomol Exp Appl 71:65-72. https://doi.org/10.1111/j.1570-7458.1994.tb01770.x

Otieno P, Pallmann P, Poehling HM (2017) Additive and synergistic interactions amongst Orius laevigatus (Heteroptera: Anthocoridae), entomopathogens and azadirachtin for controlling western flower thrips (Thysanoptera: Thripidae). Biocontrol 62:85-95. https://doi.org/10.1007/s10526-016-9767-7

Pavela R, Barnet M, Kocourek F (2004) Effect of azadirachtin applied systemically through roots of plants on the mortality, development and fecundity of the cabbage aphid (Brevicoryne brassicae). Phytoparasitica 32:286-294. https://doi.org/10.1007/BF02979823

Put K, Bollens T, Wäckers F, Pekas A (2016) Non-target effects of commonly used plant protection products in roses on the predatory mite Euseius gallicus Kreiter \& Tixier (Acari: phytoseidae). Pest Manag Sci 72:1373-1380. https://doi.org/10.1002/ps.4162

Raizada RB, Srivastava MK, Kaushal RA, Singh RP (2001) Azadirachtin, a neem biopesticide: subchronic toxicity assessment in rats. Food Chem Toxicol 39:477-483. https://doi.org/10.1016/ S0278-6915(00)00153-8

Reese JC, Tjallingii WF, van Helden M, Prado E (2000) Waveform comparisons among $\mathrm{AC}$ and DC electronic monitoring systems for aphid (Homoptera: Aphididae) feeding behavior. In: Walker GP, Backus EA (eds) Principles and applications of electronic monitoring and other techniques in the study of Homopteran feeding behaviour. Thomas Say Publications in Entomology, Entomological Society of America, Lanham, pp 70-101

Saxena RC, Khan ZR (1985) Electronically recorded distrurbances in feeding behavior of Nephotettix virescens (Homoptera: Cicadellidae) on neem oil-treated rice plants. J Econ Entomol 78:222-226. https://doi.org/10.1093/jee/78.1.222

Saxena RC, Liquido NJ, Justo HD (1981) Neem seed oil, a potential antifeedant for the control of the rice brown planthopper, Nilaparvata lugens. In: Schmutterer H, Ascher KRS, Rembold H (eds) Proceedings of the 1st In Neem Conf, Rottach-Egern 1980. German Agency for Technical Cooperation (GTZ), Eschborn, Germany, pp 171-188

Schmutterer H (1988) Potential of azadirachtin-containing pesticides for integrated pest control in developing and industrialized countries. J Insect Physiol 34:713-719. https://doi.org/10.1016/00221910(88)90082-0

Sundaram KMS (1996a) Azadirachtin biopesticide: a review of studies conducted on its analytical chemistry, environmental behavior and biological effects. J Environ Sci Health B 31:913-948. https://doi. org/10.1080/03601239609373045

Sundaram KMS (1996b) Root uptake, translocation, accumulation and dissipation of the botanical insecticide, azadirachtin, in young spruce trees. J Environ Sci Health B 31(6):1289-1306. https:// doi.org/10.1080/03601239609373068

Sundaram KMS, Campbell R, Sloane L, Students J (1995) Uptake, translocation, persistence and fate of azadirachtin in aspen plants (Populus tremuloides Michx.) and its effect on pestiferous two-spotted spider mite (Tetranychus urticae Koch). Crop Prot 14:415-421. https://doi.org/10.1016/0261-2194(95)00026-I

Sundaram KMS, Sundaram A, Curry J, Sloane L (1997) Formulation selection, and investigation of azadirachtin-A persistence in some terrestrial and aquatic components of a forest environment. Pestic Sci 51:74-90. https://doi.org/10.1002/(SICI)1096-9063(199709) 51:1\%3c74::AID-PS606\%3e3.0.CO;2-J

Szeto SY, Wan TW (1996) Hydrolysis of azadirachtin in buffered and natural waters. J Agric Food Chem 44:1160-1163. https://doi. org/10.1021/jf950575t

Therneau T (2012) A package for survival analysis in S. R package version 2.36-14

Thoeming G, Borgemeister C, Sétamou M, Poehling HM (2003) Systemic effects of neem on western flower thrips, Frankliniella occidentalis (Thysanoptera: Thripidae). J Econ Entomol 96:817-825. https://doi.org/10.1093/jee/96.3.817

Thoeming G, Draeger G, Poehling HM (2006) Soil application of azadirachtin and 3-tigloyl-azadirachtol to control western flower thrips, Frankliniella occidentalis (Thysanoptera: Thripidae): translocation and persistence in bean plants. Pest Manag Sci 62:759-767. https://doi.org/10.1002/ps.1239

Tjallingii WF (1978) Electronic recording of penetration behaviour by aphids. Entomol Exp Appl 24:721-730. https://doi.org/10.1111/j. 1570-7458.1978.tb02836.x

Tjallingii WF (1988) Electrical recording of stylet penetration activities. In: Minks AK, Harrewijn P (eds) Aphids: their biology, natural enemies and control, vol 2B. Elsevier Science Publishers, Amsterdam, pp 95-108

Tjallingii WF (1990) Continuous recording of stylet penetration activities by aphids. In: Campbell RK, Eikenbary RD (eds) Aphid-plant genotype interactions. Elsevier, Amsterdam, pp 89-99

Tjallingii WF (1994) Sieve element acceptance by aphids. Eur J Entomol 91:47-52

Tjallingii WF (2006) Salivary secretions by aphids interacting with proteins of phloem wound responses. J Exp Bot 57:739-745. https://doi.org/10.1093/jxb/erj088

Van Helden M, Tjallingii WF (2000) Experimental design and analysis in EPG experiments with emphasis on plant resistance research. In: Walker GP, Backus EA (eds) Principles and applications of electronic monitoring and other techniques in the study of Homopteran feeding behaviour. Thomas Say Publications in Entomology, Entomological Society of America, Lanham, pp 144-171

West AJ, Mordue AJ (1992) The influence of azadirachtin on the feeding behavior of cereal aphids and slugs. Entomol Exp Appl 62:75-79. https://doi.org/10.1111/j.1570-7458.1992.tb00644.x

Zuur A, Ieno EN, Walker N, Saveliev AA, Smith GM (2009) Mixed effects models and extensions in ecology with R. Springer Science \& Business Media, New York

Publisher's Note Springer Nature remains neutral with regard to jurisdictional claims in published maps and institutional affiliations. 